\title{
ARIMA-GARCH Model and ARIMA-GARCH Ensemble for Value-at-Risk Prediction on Stocks Portfolio
}

\author{
Tarno Tarno 1,*, Di Asih I Maruddani ${ }^{2}$, Rita Rahmawati ${ }^{3}$, Abdul Hoyyi ${ }^{4}$, Trimono Trimono 5 , \\ and Munawar Munawar ${ }^{6}$ \\ 1 Department of Statistics, Universitas Diponegoro, Semarang 50275, Indonesia; tarno@lecturer.undip.ac.id \\ 2 Department of Statistics, Universitas Diponegoro, Semarang 50275, Indonesia; maruddani@live.undip.ac.id \\ 3 Department of Statistics, Universitas Diponegoro, Semarang 50275, Indonesia; \\ ritarahmawati@lecturer.undip.ac.id \\ 4 Department of Statistics, Universitas Diponegoro, Semarang 50275, Indonesia; hoyyistat@live.undip.ac.id \\ 5 Department of Statistics, Universitas Diponegoro, Semarang 50275, Indonesia; trimonopujiarto@gmail.com \\ 6 Department of Statistics, Universitas Syiah Kuala Banda Aceh 23111 Indonesia; \\ munawar@stat.unsyiah.ac.id, \\ 6 PhD Program, Prince of Songkla University, Patanni Campus Thailand \\ * Correspondence: tarno@lecturer.undip.ac.id
}

Abstract: Stocks portfolio is a form of investment that can be used to minimize the risk of loss. In a stock portfolio, the value at risk $(\mathrm{VaR})$ can be predicted through the portfolio return. If portfolio return variance is heteroscedastic risk prediction can be done by using VaR with ARIMA-GARCH or Ensemble ARIMA-GARCH model approach. Furthermore, the accuracy of VaR is tested through backtesting test. In this study, the portfolio formed from Astra Agro Lestari Ltd (AALI) and Indofood Ltd (INDF) stocks from 10/02/2012 to 10/01/2019. The results showed that the best model is $\operatorname{ARIMA}(0,0,[3])-\mathrm{GARCH}(1,2)$ with AIC of -5.604 and MSE 1.874e-07.At confidence level of $95 \%$ and 1 day holding period, the $\operatorname{VaR}$ of the $\operatorname{ARIMA}(0,0,[3])-\operatorname{GARCH}(1,2)$ was -0.3464 . Based on the backtesting test, it is proven to be very accurate to predict the value of loss risk because the value of the violation ratio (VR) is equal to 0 .

Keywords: stocks portfolio, loss risk, heteroscedastic, VaR, backtesting

\section{Introduction}

Stock investment in the capital market is one form of investment which is greatly sought after by investors because stockare considered providing greater profits, have high liquidity, and are easy to transact. Basically, besides offering large and relatively fast profits, stock investment also has a risk factor for losses that can occur at any time. This is because in stock trading activities, stock prices often experience fluctuations caused by various factors. Therefore, investors must choose the right stocks that can produce maximum profits with the smallest possible risk value.

One way to minimize the risk is to do diversification. Through the diversion concept, investors are expected to be able to maximize profits and minimize the risk of loss that must be accepted. Diversification is carried out by forming a portfolio consisting of several stocks, in this case the portfolio formed is a portfolio that has a minimum risk. According to Lai (2016), the portfolio chosen by investors from several efficient portfolio choices is called the optimal portfolio. Meanwhile, 
efficient portfolios are defined by Radovic, Radukic, \& Njegomir (2018) as portfolios that produce a certain level of profit with the lowest risk, or a certain level of risk with the highest level of profit.

The value of the profits and losses of stocks portfolio investments can be seen from the value of the portfolio returns. Therefore, it is important to know the prediction of portfolio return values for future periods. Based on variance values, portfolio returns have two characteristics, namely homoscedastic (portfolio returns have constant variance values), and heteroscedastic (portfolio returns have no constant variance values). For returns with homoscedastic variance, return predictions can be modeled using the ARIMA model (Wabomba, Mutwiri, \& Fredrick, 2016). As for returns with Heteroscedastic variance, ARIMA-GARCH model or ARIMA-GARCH Ensemble can be utilized to predict the returns (Faulina\& Suhartono, 2014).

Prediction of the value of loss risk in the future period for stocks portfolio can be done using a risk measure. The risk measure used in this study is Value-at-Risk (VaR). VaR was chosen because it has several advantages. For instance, it can be used for most of the financial data (including stock price data), and has a good ability to analyze the risks critically through systematic analysis (Zhang, Zhang \& Zhao, 2019). VaR is defined as the maximum loss value of an asset in normal market conditions for a certain level of confidence and period of time.

Previous studies related to VaR and ARIMA-GARCH models among others, Siaw, Hene and Evans (2017) was constructing predictions of return value on stocks portfolios using the GARCH model, the GARCH model is considered to be very suitable for predicting return values in future periods because it provides excellent modeling predictions value. Faulina \& Suhartono (2014), used the Ensemble ARIMA-ANFIS model to predict rainfall in East Java Province, Indonesia. Kaya and Guloglu (2017) predicted the risk prediction of investment in gold, crude oil and silver commodities using the VaR GARCH model.

In this study, portfolio return predictions and VaR predictions will be performed using ARIMA-GARCH and Ensemble ARIMA-GARCH. Afterwards, the two models are compared based on the AIC and MSE values to determine the optimum model. The data used in this study is the daily stock price of Astra Agro Lestari Ltd and Indofood Ltd period of 10/02/2012 to 10/01/2019.

\section{Theoretical Framework}

\subsection{Stocks Portfolio}

Stocks portfolio is defined as a series of combinations of several single stocks that are invested and held by investors, both individuals and institutions. An efficient stocks portfolio is a portfolio that produces a certain level of profit with the lowest risk, or a certain level of risk with the highest level of profit (Husnan,1998). Most investors tend to avoid risk (risk averse), for example, investors are faced with two investments with the same expected return and different risks, then he will choose investments with lower risk levels. Suppose that, $P_{1, t}$ and $P_{2, t}$ are stochastic processes which state the price of the first and second stocks in period $t$, the stocks portfolio formed is formulated as:

$$
S_{t}=P_{1, t}+P_{2, t}
$$


Then, the portfolio return of the $S_{t}$ is obtained as follows:

$$
X_{t}=R_{1, t}+R_{2, t}
$$

where $X_{t}$ is portfolio return of $S_{t}$ in period $t . R_{1, t}$ and $R_{2, t}$ are the return of $P_{1}$ and $P_{2}$ in period $t$.

\subsection{Minimum Variance Efficient Portfolio (MVEP)}

According to Maruddani (2019), MVEP is defined as a portfolio that has a minimum variance among all possible portfolios that can be formed. If the investor's preference for risk is assumed to be risk averse, then a portfolio that has a mean variance efficient (mean variance efficient portfolio) is a portfolio that has a minimum variance of its mean return. This is the same as optimizing weights based on the maximum mean return of the given variance.

More formally, the MVEP method helps to find the weighting vector $\mathbf{w}$ so that the portfolio formed has a minimum variance based on two constraints, namely:

1. Initial specification of mean return $\mu_{p}$ has to be achieved which is $\boldsymbol{w}^{T} \boldsymbol{\mu}$.

2. Proportion number of the formed portfolios is equal to 1 that is $\boldsymbol{w}^{T} \mathbf{1}_{N}=1$, where $\mathbf{1}_{N}$ is a vector with dimension of $N \times 1$.

The optimization problem can be solved by the Lagrange function

$$
L=\boldsymbol{w}^{T} \boldsymbol{\Sigma} \boldsymbol{w}+\lambda_{1}\left(\mu_{p}-\boldsymbol{w}^{T} \boldsymbol{\mu}\right)+\lambda_{2}\left(1-\boldsymbol{w}^{T} \mathbf{1}_{N}\right)
$$

where, $L$ is Lagrange function, and $\lambda=$ Lagrange multiplier factor.

For the case of portfolios with efficient variance, there is no limitation on the portfolio mean $\left(\lambda_{1}=0\right)$, so the weighting of the MVEP with return $X \sim \operatorname{Norm}_{N}(\boldsymbol{\mu}, \boldsymbol{\Sigma})$ is

$$
\boldsymbol{w}=\frac{\Sigma^{-1} \mathbf{1}_{N}}{\mathbf{1}_{N}^{T} \Sigma^{-1} \mathbf{1}_{N}}
$$

where $\boldsymbol{\Sigma}^{-1}$ is inverse variance-covariance matrix.

\subsection{Time Series Model}

In the time series data analysis, there are two models that are used most often, ARMA and ARIMA models. Auto Regressive Moving Average (ARMA) is a combination of AR and MA models into a simpler form so that the number of parameters used remains small (Tsay, 2002). For a stochastic process $X_{t}$, the general model for the $\operatorname{ARMA}(p, q)$ process can be written as Eq.5.

$$
X_{t}=\varphi_{1} X_{t-1}+\varphi_{2} X_{t-2}+\cdots+\varphi_{p} X_{t-p}+a_{t}-\theta_{1} a_{t-1}-\theta_{2} a_{t-2}-\cdots-\theta_{q} a_{t-q}
$$

by using the backshift operator, the $\operatorname{ARMA}(p, q)$ model can be written as follows:

$$
\varphi_{p}(B) X_{t}=\theta_{q}(B) a_{t}
$$

with $a_{t} \sim N\left(0, \sigma^{2}\right)$. In addition, the $\operatorname{ARMA}(p, q)$ model is formed from stationary $\operatorname{AR}(p)$ and invertible $\mathrm{MA}(q)$ models.

Autoregressive Integrated Moving Average Model is the result of combining stationary processes with non-stationary processes that have been made stationary. The general form of the $\operatorname{ARIMA}(p, d, q)$ model is (Wei, 2006):

$$
\varphi_{p}(B)(1-B) X_{t}=\theta_{q}(B) a_{t}
$$


where

$$
\begin{gathered}
\varphi_{p}(B)=\left(1-\varphi_{1} B-\cdots-\varphi_{p} B^{p}\right)=\sum_{i=1}^{p} \varphi_{i} B^{i} \\
\theta_{q}(B)=\left(1-\theta_{1} B-\cdots-\theta_{q} B^{q}\right)=\sum_{j=1}^{q} \theta_{j} B^{j} \\
a_{t} \sim N\left(0, \sigma^{2}\right)
\end{gathered}
$$

ARIMA estimation model can utilize ACF plots and PACF plots, where the time series must be stationary.

\subsection{ARCH/GARCH Model}

In general, time series modeling must fulfill the assumption of homoscedasticity (a constant variance). However, financial data such as stock prices, currency rates, inflation rates and others usually show the phenomenon of cluster volatility, which is a period in which their prices show alternating changes for a long period followed by period indicating a stable state. The situation that previously mentioned can cause variance data not constant (Heteroscedasticity). To overcome this heteroscedasticity problem, the ARCH and GARCH models are used (Rosadi, 2012).

\section{ARCH (Autoregressive Conditional Heteroscedasticity) Model}

The ARCH (Autoregressive Conditional Heteroscedasticity) Model was firstly used to model the residual data volatility, introduced by Engle (1982). The ARCH model assumes that the residual variance at one time point is a function of the residual at another time point. According to Tsay (2002), the general form of the $\operatorname{ARCH}(p)$ model:

$$
\begin{aligned}
a_{t} & =\sigma_{t} \varepsilon_{t} \\
\sigma_{t}^{2} & =\phi_{0}+\phi_{1} a_{t-1}^{2}+\cdots+\phi_{p} a_{t-p}^{2}
\end{aligned}
$$

where $\varepsilon_{t} \sim \operatorname{Norm}(0,1), \phi_{0}>0$, and $\phi_{i} \geq 0(i=1,2, \ldots)$.

\section{GARCH (Generalized Autoregressive Conditional Heteroscedasticity) Model}

Bollerslev (1986) developed the ARCH model into a more general model known as GARCH (Generalized Autoregressive Conditional Heteroscedasticity). This model is used to overcome too large order in ARCH model. In GARCH model, conditional variance are not only influenced by past residuals but by the lag of conditional variance themselves (Ariefianto\& Doddy, 2012). Thus, the conditional variance in GARCH model consists of two components, namely the past component of the squared residual (denoted by degree $q$ ) and the past component of the conditional variance (denoted by degree $p$ ). Mathematically the GARCH model $(p, q)$ can be made in the following form:

$$
\begin{gathered}
a_{t}=\sigma_{t} \varepsilon_{t} \\
\sigma_{t}^{2}=\phi_{0}+\sum_{i=1}^{p} \phi_{i} a_{t-i}^{2}+\sum_{j=1}^{q} \phi_{j} a_{t-j}^{2}
\end{gathered}
$$

where $\varepsilon_{t} \sim \operatorname{Norm}(0,1), \phi_{0}>0$, and $\phi_{i} \beta_{j} \geq 0(i, j=1,2, \ldots), 0<\left(\phi_{i}+\beta_{j}\right)<1$. 


\subsection{Ensemble ARIMA-GARCH}

Time series prediction using combination method is a prediction technique that works by combining the output values of several prediction models as a predictive value (Zaier, Shu, Ouarda, Seidou, \& Chebana, 2010). The form of the Ensemble ARIMA-GARCH model is firstly done by determining the single ARIMA-GARCH model. The selection of models is generally based on the results of model verification/significance test parameters. Afterwards, each model will obtained $\hat{X}_{t}$ and $\hat{\sigma}_{t}^{2}$. The next process is to combine each of $\hat{X}_{t}$ and $\hat{\sigma}_{t}^{2}$ using averaging approach. Suppose $N$ is the number of single ARIMA-GARCH models, the predicted values ofEnsemble ARIMA-GARCH model are:

$$
f\left(\hat{X}_{t}\right)=\frac{1}{N} \sum_{i=1}^{N} \hat{X}_{t}^{(i)}, i=1,2, \ldots, N
$$

and

$$
f\left(\hat{\sigma}_{t}^{2}\right)=\frac{1}{N} \sum_{i=1}^{N} \hat{\sigma}_{t}^{2,(i)}, i=1,2, \ldots, N
$$

\subsection{Optimum Method Selection and Evaluation}

AIC (Akaike's Information Criterion) can be used to determine the optimum model selection. The optimum model is the model that has the smallest AIC value among other models. The formula to obtain the AIC value is written as follows (Rosadi, 2012):

$$
A I C=n \ln \left(\frac{S S R}{n}\right)+2 k,
$$

where, $n$ is the sample size, $k$ is the number of parameter model, and $S S R=\sum_{i=1}^{n} \varepsilon_{i}{ }^{2}$.

The accuracy of a model in predicting time series data can be evaluated using Mean Square Error (MSE). The MSE formula is defined as follows (Ghani \& Rahim, 2019):

$$
M S E=\frac{1}{T-T_{1}} \sum_{t=T_{1}}^{T}\left(X_{t}-\hat{X}_{t}\right)^{2}
$$

where $T$ is the total observation, $T_{1}$ is the first observation on the out-sample data, and $\hat{X}_{t}$ is the predicted value. The smaller the MSE, the better the model is used for prediction.

2.7. Value-at-Risk (VaR) in Stocks Portfolio

Value-at-risk $(\mathrm{VaR})$ is a measure of risk that is often used in finance. VaR is defined as the maximum possible value of loss over a certain period of time with a specified level of confidence. Suppose that $X_{t}$ is a stochastic process which states the value of portfolio returns at period $t$ and $X_{t}$ follows a certain distribution. The $\mathrm{VaR}$ at time $(t+1)$ with confidence level $\alpha$ can be expressed as quantile $(1-\alpha)$ from the $X_{t+1} \mid X_{t}$ distribution. VaR equation with the confidence level $\alpha$ is (Jadhav, Ramanathan \& Naik-Nimbakar, 2009):

$$
\operatorname{VaR}_{\alpha}\left(X_{t}\right)=-\inf \left\{x \in \boldsymbol{R} \mid F_{X_{t+1} \mid X_{t}}(x) \geq(1-\alpha)\right\}
$$


It has been said that the $\mathrm{VaR}$ value is the quantile value of the distribution of risk values. Therefore, VaR for continuous distribution losses can be expressed as

$$
\operatorname{VaR}_{\alpha}\left(X_{t}\right)=E\left[X_{t+1} \mid X_{t}\right]+z_{1-\alpha} \sqrt{E\left[X_{t+1}^{2} \mid X_{t}\right]-\left(E\left[X_{t+1}^{2} \mid X_{t}\right]^{2}\right)}
$$

or

$$
\operatorname{VaR}_{\alpha}\left(X_{t}\right)=\mu_{X_{t+1} \mid X_{t}}+z_{1-\alpha} \sigma_{X_{t+1} \mid X_{t}}
$$

where $z_{1-\alpha}$ is quantile $(1-\alpha)$ from the standard Normal distribution.

\subsection{Backtesting Test}

According to Danielsson (2011), backtesting test is a procedure of testing the accuracy of the VaR. Backtesting is done by taking the value of the VaR then comparing it to the actual portfolio return. If the actual return for a certain period is lower than the VaR in the same period, a violation is said to occur. Hence, measuring the quality of VaR forecasting can be done by comparing the number of violations that occur with the number of violations expected or what is more commonly referred to as the Violation Ratio (VR). The VR is calculated by comparing the number of violations $v_{1}$ with the expected number of violations. The VR formula is given by following equation:

$$
V R=\frac{v_{1}}{m_{0} \times K_{u}}
$$

$m_{0}$ is the probability of a suspected violation, and $K_{u}$ is the length of the test window. If the value of $\mathrm{VR}=1$, then the number of violations that occur is the same as the expected number of violations (VaR calculation method gives the right risk estimation results). If $\mathrm{VR}>1$, the violations that occur are greater than the expected number of violations. Meanwhile, $V R<1$ indicates that the violations that occurred are fewer than the expected number of violations.

\section{Research Methods}

\subsection{Data Source}

The data used in this study is the return data from the closing price of two stocks listed on Indonesia Stock Exchange (IDX) in plantations and food sector. Those two stocks areAstra Agro Lestari Ltd (AALI) and Indofood Ltd (INDF) for the period of 10/02/2012 to 10/01/2019. There are 1741 data returns divided into two groups. The first group is in-sample data (1721 data), the second group is out-sample data (20 data). Data was obtained from https://finance.yahoo.com/.

\subsection{Method of Analysis}

The steps taken for data analysis were as follows: (1) The value of stock returns was calculated. (2) The weight of the stocks portfolio was calculated using the MVEP method. (3) The stocks portfolio returns were calculated. (4) The stocks portfolio data were divided into in-sample and out-sample data. (5) Stationarity test in the mean for in-sample data was carried out. (6) The ARIMA model was formed through ACF and PACF plots. (7) The ARIMA model was verified. (8) The effect of GARCH on the ARIMA model through the Lagrange Multiplier test was identified. (9) The ARIMA-GARCH model was formed. (10) Optimum ARIMA-GARCH model was chosen by 
comparing the AIC value. (11) The Ensemble ARIMA-GARCH model was formed. (13) The model was evaluated through MSE values. (14) Predicted VaR for the optimum model.

\section{Results and Discussion}

In the prediction of return and VaR for stocks portfolio, the first step begins with a time series plot and descriptive statistics from a single stock data. The objective of this is to know the characteristics of the data that will be used to form a stock portfolio, in addition to also see whether there are outliers in the data that will be used to form a stocks portfolio. The time series plot for AALI and INDF stocks price data is presented as Figure 1.
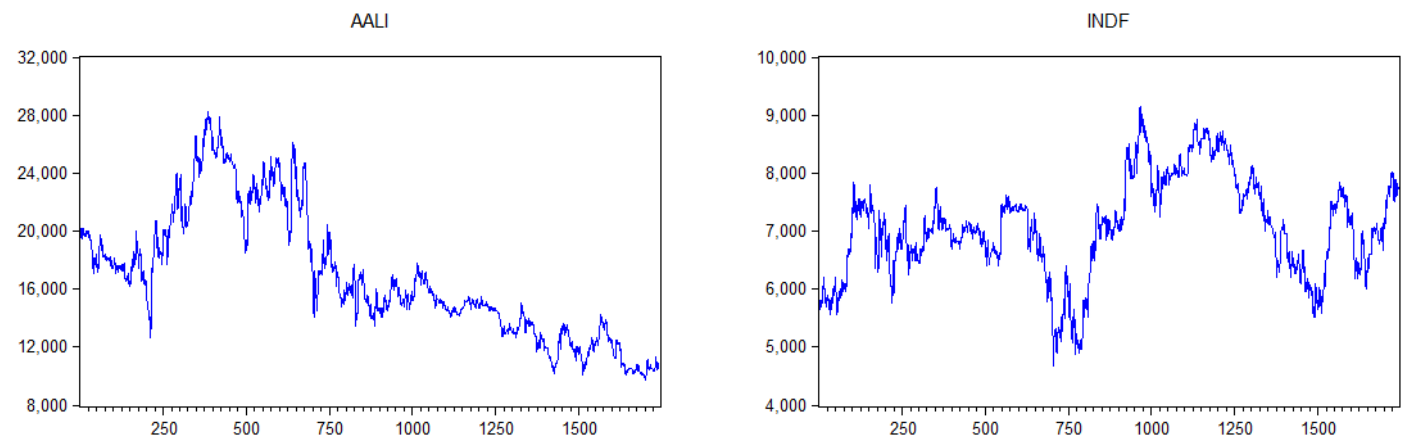

Figure 1. Time series plot of AALI and INDF

Based on Figure 1, it can be seen that during the period of 10/02/2012 to 10/01/2019, AALI tend to decrease in value while INDF have a tendency to increase in value, this can be an indication that the correlation is negative. With pearson corellation test, The correlation formed between AALI and INDF was -0.1034 .

In stocks portfolios, portfolio return is obtained from the aggregation between AALI and INDF return. Figure 2 is a time series plot for AALI and INDF return. Figure 2 shows that there are no outliers visually in AALI and INDF return data, other than that, the data has a tendency to be stationary because its value spreads around the mean.
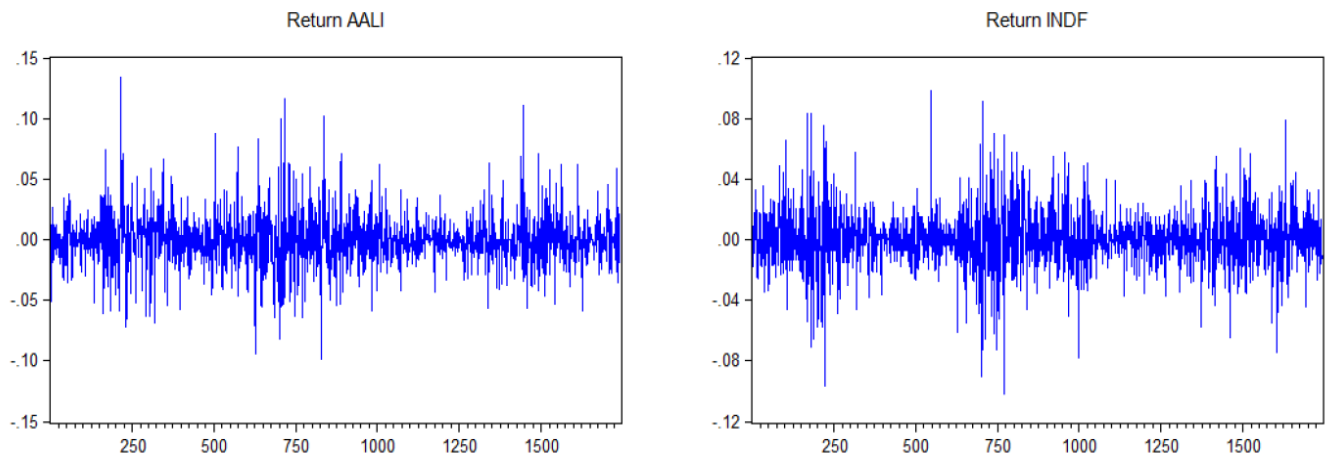

Figure 2. Data return time series plot of AALI and INDF shares 
One method that can be used to form an optimum portfolio weight is the MVEP method. The weighting results using the MVEP method for AALI and INDF are 0.4105 and 0.5895 respectively. In other words, the proportion of investment in the portfolio to obtain the maximum profit is $41.05 \%$ invested in AALI, and the remaining. 58.95\% is invested in INDF. Figure 3 is a time series plot of the portfolio return.

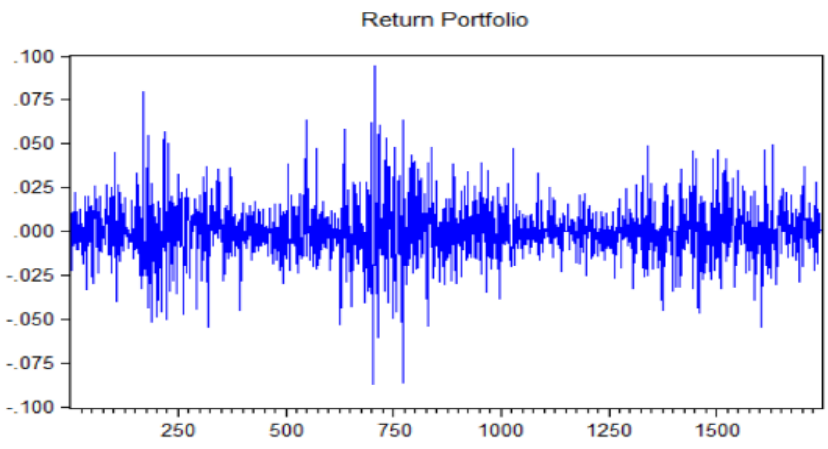

Figure 3. Time series plot of portfolio return

The portfolio return plot shows that the data tend to be stationary in mean, because throughout the observation period the data distribution was around the mean value. Formally, data stationarity is tested through the ADF-test, the ADF-test results are presented as Table 1 . Referring to Table $1, H_{0}$ for the ADF-test is rejected, this means that formally the portfolio returns are stationary in mean.

Table 1. Stationary test in mean for portfolio return

\begin{tabular}{cccc}
\hline \hline ADF Value & Significance Level & p-value & Decision \\
\hline-39.0596 & $5 \%$ & 0.0000 & data is stationary in mean \\
\hline \hline
\end{tabular}

Based on ACF and PACF plots for portfolio return data, the possible ARIMA models formed are ARIMA([3],0,0), ARIMA (0,0,[3]), and ARIMA ([3],0,[3]). Table 2 shows the estimated parameter values for the three models.

Table 2. Estimated parameter of ARIMA model

\begin{tabular}{cccc}
\hline \hline Model & & Estimates & p-value \\
\hline ARIMA $([3], 0,0)$ & $\phi_{3}$ & -0.08473 & 0.0000 \\
ARIMA $(0,0,[3])$ & $\theta_{3}$ & -0.08484 & 0.0000 \\
ARIMA $([3], 0,[3])$ & $\phi_{3}$ & -0.02831 & 0.9022 \\
& $\theta_{3}$ & -0.05697 & 0.8041 \\
\hline \hline
\end{tabular}

The parameter estimation of ARIMA model resulting that the parameters in ARIMA $([3], 0,0)$ and $\operatorname{ARIMA}(0,0,[3])$ models are significant at the level $\alpha=5 \%$. Meanwhile, for the $\operatorname{ARIMA}([3], 0,[3])$ model the parameters formed are not significant, because the $\mathrm{p}$-value for each parameter is greater than $\alpha=5 \%$. Therefore, the models that pass the model verification are $\operatorname{ARIMA}([3], 0,0)$ and $\operatorname{ARIMA}(0,0,[3])$. 
Furthermore, for each model that passes the model verification, a residual assumption test will be conducted which includes tests of normality, independence, and homoscedasticity test. The results of the model residual test shown in Table 3 conclude that the assumptions of normality and homoscedasticity are not fulfilled.

Table 3. Residual tests for ARIMA models

\begin{tabular}{cccc}
\hline \hline \multirow{2}{*}{ Models } & \multicolumn{3}{c}{ Residual Test } \\
\cline { 2 - 4 } & Normality & Independency & Homoscedasticity \\
\hline ARIMA $([3], 0,0)$ & $\times$ & $\checkmark$ & $\times$ \\
ARIMA $(0,0,[3])$ & $\times$ & $\checkmark$ & $\times$ \\
\hline \hline
\end{tabular}

The only assumption fulfilled is the residual independence assumption. The unfulfilled homoscedasticity assumption indicates that the residual variance of each model is not constant. Therefore, it needs to be modeled with the ARCH/GARCH model. Based on the model verification for $\mathrm{ARCH} / \mathrm{GARCH}$ model through the signification test parameter, at the significance level $\alpha=5 \%$, it was found that there were 11 models that passed the verification, those are $\operatorname{ARIMA}([3], 0,0)$ $\operatorname{ARCH}(1), \operatorname{ARIMA}([3], 0,0)-\operatorname{ARCH}(2), \operatorname{ARIMA}([3], 0,0)-\operatorname{GARCH}(1,1), \operatorname{ARIMA}([3], 0,0)-\operatorname{GARCH}(1,2)$, $\operatorname{ARIMA}([3], 0,0)-\operatorname{GARCH}(2,1), \operatorname{ARIMA}(0,0,[3])-\operatorname{ARCH}(1), \operatorname{ARIMA}(0,0,[3])-\operatorname{ARCH}(2), \operatorname{ARIMA}(0,0,[3])-$ $\operatorname{GARCH}(1,1), \operatorname{ARIMA}(0,0,[3])-\operatorname{GARCH}(1,2)$, and ARIMA(0,0,[3])-GARCH$(2,1)$.

The optimum model for portfolio returns prediction is chosen based on the AIC value, provided that the optimum model is the model with the smallest AIC value. The AIC value for each model can be seen in Table 4. It is known that the optimum model is $\operatorname{ARIMA}(0,0,[3])-\operatorname{GARCH}(1,2)$ because it has the smallest AIC of -5.604 .

Table 4. Evaluation of ARIMA-GARCH model

\begin{tabular}{cccc}
\hline \hline Models & AIC & Models & AIC \\
\hline ARIMA([3],0,0)-ARCH(1) & -5.4793 & ARIMA(0,0,[3])-ARCH(1) & -54790 \\
ARIMA([3], 0,0)-ARCH(2) & -5.5140 & ARIMA(0,0,[3])-ARCH(2) & -5.5137 \\
ARIMA([3],0,0)-GARCH(1,1) & -5.5934 & ARIMA(0,0,[3])-GARCH(1,1) & -5.5936 \\
ARIMA([3],0,0)-GARCH(1,2) & -5.6034 & ARIMA(0,0,[3])-GARCH(1,2) & -5.6036 \\
ARIMA([3],0,0)-GARCH $(2,1)$ & -5.5962 & ARIMA(0,0,[3])-GARCH(2,1) & -5.5964 \\
\hline
\end{tabular}

Representations of the ARIMA $(0,0,[3])-\operatorname{GARCH}(1,2)$ model are as follows:

$$
\begin{aligned}
& \hat{X}_{t}=a_{t}-0.0931 a_{t-3} \\
& \hat{\sigma}_{t}^{2}=1.51 \times 10^{-6}+0.1769 a_{t-1}^{2}-0.1352 a_{t-2}^{2}+0.9533 \sigma_{t-1}^{2}
\end{aligned}
$$

For every ARIMA-GARCH models that are signed, the Ensemble ARIMA-GARCH Ensemble model can be formed. The ARIMA-GARCH Ensemble model formula for mean prediction can be written as Eq.22.

$$
f\left(\hat{X}_{t}\right)=\frac{1}{10} \sum_{i=1}^{10} \hat{X}_{t}^{(i)}
$$


Whereas the Ensemble ARIMA-GARCH for variance prediction is formulated by Eq. 23.

$$
f\left(\hat{\sigma}_{t}^{2}\right)=\frac{1}{10} \sum_{i=1}^{10}\left(\hat{\sigma}_{t}^{2}\right)^{(i)}
$$

The results of portfolio return prediction and its variance values using the ARIMA $(0,0,[3])$ GARCH $(1,2)$ and Ensemble ARIMA-GARCH models are shown in Table 5.

Table 5. Portfolio return prediction

\begin{tabular}{ccccc}
\hline \hline \multirow{2}{*}{ Period } & ARIMA(0,0,[3])-GARCH(1,2) & \multicolumn{2}{c}{ Ensemble ARIMA-GARCH } \\
\cline { 2 - 5 } & $\hat{X}_{t}$ & $\hat{\sigma}_{t}^{2}$ & $\hat{X}_{t}$ & $\hat{\sigma}_{t}^{2}$ \\
\hline $09 / 03 / 19$ & -0.00061 & 0.000117 & -0.00068 & 0.000145 \\
$09 / 04 / 19$ & -0.00054 & 0.000124 & -0.00055 & 0.000151 \\
$09 / 05 / 19$ & -0.00013 & 0.000118 & 0.00079 & 0.000141 \\
$09 / 06 / 19$ & 0.00073 & 0.000111 & 0.00079 & 0.000141 \\
$09 / 10 / 19$ & -0.00056 & 0.000106 & -0.00055 & 0.000136 \\
$09 / 11 / 19$ & 0.00033 & 0.000104 & 0.00035 & 0.000135 \\
$09 / 12 / 19$ & 0.00008 & 0.000141 & 0.00005 & 0.000171 \\
$09 / 13 / 19$ & -0.00026 & 0.000193 & -0.00024 & 0.000226 \\
$09 / 16 / 19$ & 0.00143 & 0.000118 & 0.00147 & 0.000161 \\
$09 / 17 / 19$ & 0.00209 & 0.000239 & 0.00217 & 0.000263 \\
$09 / 18 / 19$ & -0.00021 & 0.000236 & -0.00021 & 0.000274 \\
$09 / 19 / 19$ & -0.00248 & 0.000150 & -0.00265 & 0.000190 \\
$09 / 20 / 19$ & -0.00224 & 0.000156 & -0.00243 & 0.000179 \\
$09 / 23 / 19$ & -0.00030 & 0.000162 & -0.00030 & 0.000185 \\
$09 / 24 / 19$ & 0.00081 & 0.000151 & 0.00095 & 0.000178 \\
$09 / 25 / 19$ & 0.00103 & 0.000202 & 0.00117 & 0.000226 \\
$09 / 26 / 19$ & 0.00077 & 0.000168 & 0.00082 & 0.000199 \\
$09 / 27 / 19$ & 0.00179 & 0.000157 & 0.00182 & 0.000183 \\
$09 / 30 / 19$ & -0.00108 & 0.000141 & -0.00117 & 0.000166 \\
$10 / 01 / 19$ & -0.00082 & 0.000136 & -0.00089 & 0.000160 \\
\hline \hline
\end{tabular}

Accuracy is an important element in the prediction of time series data, a good prediction model should have high degree of accuracy. The higher the accuracy of a model, the closer the predicted value to the actual value. In this study, prediction accuracy was measured using MSE values. MSE values are presented in Table 6. 
Table 6. Comparison of MSE value

\begin{tabular}{cc}
\hline \hline Model & MSE \\
\hline ARIMA(0,0,[3])-GARCH(1,2) & $1.874 \times 10^{-7}$ \\
Ensemble ARIMA-GARCH & $2.558 \times 10^{-7}$ \\
\hline \hline
\end{tabular}

Based on Table 6, models with smallest MSE value is ARIMA(0,0,[3])-GARCH(1,2). Accordingly, this model is the optimum model to predict portfolio return. Basically, stocks portfolio investment still contains an element of risk of loss, so it is important for investors to know the estimated risk of loss in the coming period. Predicted losses using the VaR method with $95 \%$ of confidence level in the stock portfolio are presented in Table 7.

Table 7. VaR prediction of stocks portfolio

\begin{tabular}{cccc}
\hline \hline Period & $\widehat{\operatorname{VaR}}_{95 \%}$ & Period & $\widehat{\operatorname{VaR}}_{95 \%}$ \\
\hline $09 / 03 / 19$ & -0.0184 & $09 / 18 / 19$ & -0.0255 \\
$09 / 04 / 19$ & -0.0189 & $09 / 19 / 19$ & -0.0226 \\
$09 / 05 / 19$ & -0.0180 & $09 / 20 / 19$ & -0.0228 \\
$09 / 06 / 19$ & -0.0166 & $09 / 23 / 19$ & -0.0212 \\
$09 / 10 / 19$ & -0.0175 & $09 / 24 / 19$ & -0.0194 \\
$09 / 11 / 19$ & -0.0164 & $09 / 25 / 19$ & -0.0224 \\
$09 / 12 / 19$ & -0.0195 & $09 / 26 / 19$ & -0.0205 \\
$09 / 13 / 19$ & -0.0231 & $09 / 27 / 19$ & -0.0188 \\
$09 / 16 / 19$ & -0.0164 & $09 / 30 / 19$ & -0.0206 \\
$09 / 17 / 19$ & -0.0233 & $10 / 01 / 19$ & -0.0200 \\
\hline
\end{tabular}

Backtesting procedure was used to test the accuracy of $\mathrm{VaR}$ in predicting the risk of loss. Through the procedure, violation ratio (VR) obtained is equal to 0 . It can be concluded that in VaR calculation period (09/03/19 to 10/01/19) there was no actual loss value that was greater than the predicted VaR value. So, it can be said that VaR has very good accuracy in predicting the risk of loss for stock portfolio.

\section{Conclusion}

Based on the analysis results and discussion, it is concluded that the optimum investment weight in the stocks portfolio are $49.05 \%$ of investment funds is allocated for investment in AALI stock, and the remaining $58.95 \%$ is allocated for INDF stock. The optimum model that can be used to predict the value of portfolio returns is $\operatorname{ARIMA}(0,0,[3])-\mathrm{GARCH}(1,2)$ model with AIC values of -5.604 and MSE 2.558 $\times 10^{-7}$. By using VaR, the prediction of loss risk for the period of 10/02/2019 with confidence level $\alpha=95 \%$ is 0.020 . Through the backtesting procedure, VaR is proven to have very 
good accuracy in predicting risk, this is proved by the value of the violation ratio (VR) obtained which is equal to 0 .

Acknowledgements. This research is officially granted by Universitas Diponegoro in 2019 with contract number 1590/UN7.5.8/HK/2019.

\section{References}

Ariefianto \& Doddy, M. 2012. Econometrics Essence and Applications with EViews. Jakarta: PT. Gelora Aksara Pratama.

Bollerslev. 1986. Generalized Autoregressive Conditional Heteroscedasticity. Journal of Econometrics, 31, 307-327. doi: 10.1016/0304-4076(86)90063-1

Daniel, W. W. 1989. Applied Nonparametric Statistics. Subtitles by Alex Tri Kantjono Widodo. Jakarta: Gramedia.

Engle, R. F. 1982. Autoregressive Conditional Heteroscedasticity with Estimates of the Variance of United Kingdom Inflation. Journal of Econometrica, 50(4), 987-1008. doi: 10.2307/1912773

Faulina, R., \& Suhartono. 2013. Hybrid ARIMA-ANFIS for Rainfall Prediction in Indonesia. International Journal of Science and Research (IJSR), 2(2), 159-162. doi: 10.31219/osf.io/vw8rx

Ghani, I. M. Md, \& Rahim, H.A. 2019. Modeling and Forecasting of Volatility using ARMA-GARCH: Case Study on Malaysia Natural Rubber Prices. IOP Conf. Ser.: Mater. Sci. Eng. 548012023.doi: 10.1088/1757-899X/548/1/012023

Husnan, S. 1998. Elementary Portfolio Theory and Security Analysis. Second Edition. Yogyakarta: UPP-AMP YKPN.

Jadhav, D., Ramanathan, T.V., \& Naik-Nimbakar, U.V. 2009. Modified Estimators of the Expected Shortfall. Journal of Emerging Market Finance, 8(2): 87-107. doi: 10.1177/097265270900800201

Kaya, P., \& Guloglu, B. 2017. Modeling and Forecasting the Markets Volatility and VaR Dynamics of Commodity. Journal of BRSA Banking and Financial Markets, 11(1), 9-49.

Lai, K. 2016. Selecting an Optimal Portfolio for Investment in Stocks in India: A Sectoral Approach. Pacific Business Review International, 8(9).

Maruddani, D.A.I. 2019. Value at Risk for Risk Measures on Stock Investment. Ponorogo: Wade Group.

Radovic, M., Radukic, S., \& Njegomir, V. 2018. The Application of the Markowitzs Model in Efficient Portfolio Forming on the Capital Market in the Republic of Serbia. Economic Themes, 56(1), 17-34. doi: 10.2478/ethemes-2018-0002

Rosadi, D. 2012. Econometrics and Applied Time Series with EViews. Yogyakarta: Andi Offset.

Siaw, R.O., Hene, E.D.O., \&Evans, T. 2017. Investment Portfolio Optimization with GARCH. ELK Asia Pacific Journal of Finance and Risk Management, 8(2). doi: 10.16962/EAPJFRM/issn. $2349-2325 / 2015$

Tsay, R. S. 2002. Analysis of Financial Time Series. New York: John Willey and Sons, Inc. 
Wei, W.W.S. 2006. Time Series Analysis, Univariate and Multivariate Methods. Canada: Addison Wesley Publishing Company.

Wabomba, M.S., Mutwiri, M.P., \& Fredrick, M. 2016. Modelling and Forecasting Kenyan GDP Using Autoregressive Integrated Moving Average (ARIMA) Models. Science Journal of Applied Mathematics and Statistics. 4(2), 64-73. doi:10.11648/j.sjams.20160402.18

Zaier, I., Shu, C., Ouarda, T., Seidou, O., \& Chebana, F. 2010. Estimation of ice thickness on lakes using artificial neural network ensembles. Journal of Hydrology, 383,330-340.doi: 10.1016/j.jhydrol.2010.01.006

Zhang, W., Zhang, S., \& Zhao, P. 2019. On Double Value at Risk. Journal of Risk. 7(31) doi: 10.3390/risks 7010031 